\title{
DOCUMENTÁRIO
}

MEMÓRIA HISTÓRICA SÔBRE CANANÉIA (XV).

(Continuação) .

ANTONIO PAULINO DE ALMEIDA

da Socledade de Estudos Históricos.

CAPITULO XLIV.

\section{A LAGOA DOURADA.}

Sendo conhecida, não só em Cananéia, como em tôda a região sul paulista a lenda sôbre a "lagoa dourada", procuramos conhecer os velhos alfarrábios da Câmara Municipal, onde nada existe sôbre o assunto que tanto empolgou o espírito do povo, que ainda hoje o guarda na lembrança.

Em 1926, viajando de Paranaguá para Curitiba, em conversa com o ilustre e saudoso amigo dr. Pânfilo de Assunção, tivemos ocasião de falar sôbre o assunto, dizendo-nos o mesmo recordar-se de haver lido algo a êsse respeito, em um antigo jornal que se publicara em Iguape.

Dirigimos-nos ao velho amigo Valdomiro Fortes, ali residente e já falecido, e que conservava em seu arquivo particular muitas publicações e manuscritos, e êle nos informou haver encontrado a seguinte e interessante notícia escrita pelo padre José Alves Carneiro, que por muitos anos foi vigário daquela cidade.

"Diz uma lenda antiga, que paira na lembrança de pessoas de bem e de muito critério e testemunho, que no anno de 1627, appareceu nesta villa, (de Iguape) um velho marinheiro desertor, que havia fugido da perseguição, e que constava haver commettido qualquer delito, apresentou-se com uma boa amostra de ouro envolvida em folhas de caitês, e disse que entre os Itatins o morro de Botucavarú, encontrou uma lagôa, tão cheia de ouro, que até os caitês se achavam cobertos desse metal e que era extraordinaria a quantidade do mesmo, e que dava para cobrir as ruas da villa. Disse mais que passou um dia nessa lagôa e levantava o ouro ás mãos cheias do seu leito". 
Afirmavam outras pessoas de que nos velhos manuscritos da Câmara da antiga Vila havia referências sôbre a mesma lagoa, nada mais adiantando sôbre o assunto.

Em Cananéia, dos documentos que conseguimos ler, apenas em um dêles consta a notícia da existência de uma lagoa no cimo mais alto do Cardoso, notícia esta que consta ainda de várias publicações e até mesmo de um Relatório de antiga Comissão de Estatística, publicado em 1887.

Entretanto, examinando livros e papéis do Arquivo do Estado encontramos o seguinte (223):

Illmo. e Exm? Senhor.

Diz o Alferes João de Deos Miz Claro da Villa de Paranahyba desta Com.ca, que tenco chegado a seo poder atradição, deq' trata oRoteiro incluso, tomou a sua conta fazer todos os exames nescessarios pa. descubrir olugar aurifero, asignallado nom.mo Roteiro; nesta deligencia tem o Supp.e empregado por espaço de sette annos com notavel trabalho, edispesa, eachando-se nesta deligencia entrarão repentinamente outros Aventureiros, hum denome Joaquim detal, eoutro de cognome Leme, epouco distante dehum dos Lugares examinados pelo Supp.e pa. o. lado deSul descubrirão olugar, q' sengudo as enformações q' o Supp.e pode obter he om.mo Lugar desejado e anunciado no Roteiro; ecomo os Suppd.os ocultão este descobrim. to e o Supp.e pertende examinar para, sendo verdadeiro, dar amanifesto e serepartir pelo Povo na Conformid. das Reas Ordens, porisso deseja ser authorisado pa. no lugar onde seachão trabalhando, fazer os exames nescessarios, obrigandose avir dar conta de todo resultado pa. sedarem as providencias que forem de direito, e nestes termos,

P. a V. Exa. seja servido mandar expedir afavor do Supp.e Portaria pa. om.mo hir fazer os refferidos exames, semq' os Suppd.os ou outra ql.qr. pessoa opossa embaraçar, cuja providencia alem dejusta, talver q' seja de grande vantagem ao Estado.

E. R. M.ce

O requerimento acima traz o seguinte despacho:

Informe com o seu parecer o Dez.or Ouv.dor da Comarca de Itú e satisfeito defferirei ao Sup.e como mais conveniente for ao Serviço de S. Mag.e e ao Interesse Publico. S. Paulo em 11 de Setembro de 1816.

Depois vem à página 3 :

(223). - Maço 75 (T. C.), pasta 1, documento ne 30. 


\section{Informação}

Manoel da Cruz Correa da Silva Cap. Mor nesta Villa de Santa Anna de Parnahiba por Sua Mag. e nam.ma Juiz Ordinr.o por bem das Ordenaçoins dom.mo Senhor que Deos ge. etc. etc.

Attesto, efaço certo que o Alfr.s João de Deos Miz Claro, m.or no Destricto do meu comando, a sette annos tem andado na deligencia do descubrim.to de ouro em pó nos mattos de Juquiá Guassú, entre a fronteira de Iguape, e Vutucavarú, fazendo as suas entradas pella resaca de Pereatuva, a custa de sua fazenda, com o maior esforço, e excecivo disvelo / segundo me cocnsta / só afim de querer descobrir os tesouros incobertos para o aumento da Real Fazenda, e dos Povos necessitados, cujo exforço o tem mostrado, não só por ser dotado de huma natural inclinação desde sua infancia; como tambem tem sido sempre pronpto na execução das ordens do Real Serviço, quando lhe hé encarregado.

E por me ser esta pedida a passo de minha Letra e Signal.

Villa de Parnahiba 8 de Setembro de 1816.

Manoel da Cruz Corr.a da S.a 124

Pg. 100 rs. de Sello. S. P. 11 de Setembro de 1816.

Mor.a

Por se interessante damos abaixo o manuscrito seguinte que se encontra junto:

\section{Roteiro Antigo}

Entre Sorocaba, Itapitininga, Iguape e Uvutucavaru: nestes sertoins á perto de duzentos annos, mais, ou menos achou hum antigo segundo as noticias q' propoz estando ao fim da vida: mandou escrever assim.

Seguindo-se pela reçaca dos Campos de Pereatuba, entre Sul, e Leste, passando dois ribeiroins, e duas serras; adiante se dá com hum ribeiro, q' p.a as cabeceiras tem hum meio descalvado, ou bastante pedras. Dobrando-se amesma serra está outro ribeiro q' pela cachueira acima tiramos oiro em pedassos: e seguindo p.a diante, mais ao lado do Sul se dá com hum vargido, q' com 4 ou 5 palmos q' se tire de lodo se acha $m$. to bom cascalho, e oiro com muita conta. E logo adiante subindo, edecendo algumas serras não mui incantiladas, está huma Lagoa grande, q' feito hum socovão -na beira setirou oiro em pedassos, emuitas pedras q' me parecião preciozas.

E a lenda que veio dos tempos coloniais, perdura ainda, empolgando o espírito de muita gente boa... 


\section{CAPITULO XLV. MÔRRO DO CASTIGO.}

No município de Cananéia, como já temos dito, cada ruína encerra uma história, cada recanto evoca um poema.

E' assim que, segundo a História, não passou de um castigo o naufrágio de um navio que zarpara do pôrto do Rio de Janeiro, indo naufragar junto às costas de Cabo Frio. Salvos do naufrágio, embarcaram os tripulantes em escaleres e, fugindo à saida dos índios ferozes, que habitavam aquela região, rumaram para o sul, indo entrar na barra de Cananéia.

Tal acontecimento, como diz Vieira dos Santos, foi tomado como castigo, por haver o pilôto de bordo, durante a viagem, asseverado que, da náutica, sabia mais do que São João Batista...

Também o incêndio do vapor "Conde d'Aquila" - ocorrido diante da Vila no dia 4 de maio de 1858 , foi atribuido a um castigo, por haver um dos seus tripulantes declarado durante a missa na Igreja de São João Batista, que as tíbias da Imagem seriam muito boas para acender $o$ fogo das fornalhas de bordo...

No dia imediato, queimava-se o belo navio de passageiros, diante da Vila, onde, há poucos anos eram vistos os seus últimos destroços.

Assim, aos que navegam pelo interior da baía de Trapandé, não passa desapercebido o môrro da "Parada", fronteiro à ilha da Casca. Como os seus vizinhos, do Andrade, do Jacareú, etc. era outrora coberto de vegetação luxuriante, com árvores frondosas e matas opulentas .

Aconteceu, porém, que, sendo o seu proprietário homem avesso à religião, para castigar à rebeldia dos escravos, que desejavam guardar os dias santificados, entendeu obrigá-los ao trabalho no dia 6 de agôsto, quando na cidade de Iguape se comemora o encôntro da Imagem do Senhor Bom Jesus. Foi assim que, nesse dia, consagrado às festividades em louvor ao Santo Padroeiro de Iguape, efetuava-se na fazenda da Parada a queima de uma grande roça que abrangia todo o môrro. Essa determinação foi largamente comenta$\mathrm{da}$, não só na vila de Cananéia, como em tôda a região, pois naqueles bons tempos, tal deliberação assumia às proporções de um verdadeiro sacrilégio e desrespeito a Deus.

Concluiu-se o trabalho. A roça foi plantada sem outro qualquer incidente, além dos comentários que em tôrno do fato se fizeram.

Qual não foi, porém, a surpresa do teimoso senhor ao aproximar-se a época da colheita! 
Nada!. . Nem mesmo a antiga vegetação tornou à terra assim lavrada, onde, em vez da mata natural ou dos cereais ali plantados, surgiu enorme sapezal, que ainda hoje se apresenta aos olhos do povo!

Nunca mais àquela terra, outrora produtiva, voltou a enxada do lavrador, passando o pitoresco môrro da Parada a denominar-se "Morro do Castigo", como é conhecido em tôda a região.

Fugiram os dias, passaram-se os anos, porém, o tempo que tudo consome, não conseguiu apagar da memória dos homens a lembrança desse fato, que se recorda a cada instante, enquanto as canoas, de velas pandas vão passando pela magestosa baía de Trapandé...

\section{* * \\ CAPITULO XLVI TRADIÇÕES.}

Antes do estabelecimento da linha de navegação fluvial Iguape-Cananéia, e principalmente da estrada de ferro Santos-Juquiá, tôda a comunicação entre esta última cidade e os demais centros da região era realizada através de maus caminhos, sendo que o único meio de transporte se fazia por via marítima, em pequenos vapores costeiros, que apenas duas vêzes por mês escalavam regularmente nos referidos portos.

Dessa maneira e na falta de vias terrestres, vivia a pequenina cidade do litoral sul paulista como que segregada do mundo exterior, conservando os seus usos e costumes, afastada do convívio de pessoas estranhas, silenciosa e calma, alheia à onda de progresso que invadia a região do planalto, favorecida pela passagem dos caminhos de ferro.

Até então não se haviam rompido os laços que a prendiam ao passado, que evocavam no seio de seus habitantes velhas tradições há muitos anos em pleno desuso em quase todos os recantos do território do Estado.

Eram o entrudo, com os seus limões de água de cheiro para as pessoas da elite social, baldes e latas de água e carimás, entre a gente pobre; as fogueiras de Santo Antônio, São João e São Pedro, com buscapés, bichas e pistolões multicores, para os mais afortunados, enquanto que os que não dispunham de recursos, contentavam-se com as fôlhas de mangue manso lançadas ao fogo, em substituição às barulhentas e perigosas bombas. 
No decorrer dos anos, entretanto, tais folguedos foram a pouco e pouco perdendo aquêle sabor antigo, enquanto que outros, como as famosas congadas, desapareciam por completo.

As folias do Divino, antes admiráveis pelo seu conjunto, muito embora ainda empregadas para a coleta de esmolas no município, não passam agora de uma pálida imagem do que foram em outros tempos, quando respeitadas e empolgantes, percorriam as ruas da cidade, esmolando de casa em casa, com enorme acompanhamento de fiéis.

Entretanto, nos últimos anos, em virtude do prolongamento da linha de vapores da Fluvial até Ararapira, abertura de estradas e melhoria da navegação entre os portos do litoral, passou Cananéia a ser frequientada por numerosos visitantes, alguns dos quais observavam tais práticas com simples desdém, enquanto que outros procuravam ridicularizá-las, do que resultou certo movimento de repúdio por parte da própria população, que, nos últimos anos mal admite o emprêgo das folias que agora apenas andam pelos sítios e, em seu regresso, esmolam nas casas do Rocio, já desfalcadas de alguns dos seus antigos elementos, sem aquêle brilho e respeito dos velhos tempos, quando os mestres foliões eram tidos como homens de grandes merecimentos.

Das festas do Divino Espírito Santo com os seus setenários (sete) trajetos tôdas as noites, com mesas de doces ao regressar da Igreja, fogos de bengala que os abrilhantavam, apenas restam o ato do império, com o oferecimento de uma simples mesa de doces e o aparatoso ato do pedido de esmolas, em que aparecem numerosas bandeiras conduzidas por senhoritas. Quanto aos famosos trajetos, resta apenas a primeira no início da festa, da casa do imperador para a igreja, de onde voltam as bandeiras e a corôa na véspera da abertura do império, que tem lugar logo após ao pedido de esmolas .

Quanto aos setenários (sete), como medida econômica ficaram reduzidos a dois, da mesma forma que as novenas de São João Botista .

Assim tais festividades que antes no dia 16 de junho, começavam pelas novenas de São João, logo ao por do sol, e, dois após com os setenários do Divino, que se realizavam meia hora depois das novenas, ficaram reduzidos a dois, cada um dêles, realizando-se os setenários nos dias 20 e 22 e as novenas a 21 e 23 , mesmo porque a população do município dando preferência às festas em louvor de Nossa Senhora dos Navegantes, deixou de comparecer àquelas, que por isso perderam o seu costumado resplendor.

Quanto às festas de Nossa Senhora dos Navegantes, que hoje é a mais importante de tôdas devido à procissão marítima que per- 
corre tôda a baía de Cananéia e atrai àquela cidade romeiros de tôda a parte, foi instituida há poucos anos pelo padre Alaim Petibon, bretão de origem.

A imagem foi adquirida em São Paulo no ano de 1909, por conta dos cananeenses Capitão Ernesto Martins Simões, Izaac Vilalva de Almeida, Luís Mateus de Almeida e João Delfino de Oliveira, sendo levada para Cananéia pelo nosso amigo Sílvio Carneiro de Almeida Braga, que ali chegou a 5 de dezembro de 1909, pelo vapor "Garcia".

No dia 12 de agôsto tinha lugar o seu batismo pelo padre Colombano, servindo de padrinhos as Imagens de Santo Antônio e de Nossa Senhora da Conceição, ficando encarregados da primeira festa, os srs. capitão Ernesto M. Simões, Luís M. de Almeida e João Delfino de Oliveira.

E a 15 de agôsto de 1909, assistia Cananéia, pela primeira vez, a procissão marítima, que, partindo do cais municipal pelas 3 horas da tarde, percorria tôda a baía, sendo conduzida, a gloriosa imagem, pelo hiate "Novo Pernambuco", de que era Mestre o sr. Augusto de Souza.

Desde então, vem a histórica cidade praiana assistindo ao desenvolvimento cada vez mais acentuado, do culto pela Virgem dos Navegantes, cujas festividades atraem todos os anos um número cada vez maior de forasteiros, sobretudo, de embarcações procedentes de todos os portos do litoral paulista e até mesmo do Paraná e Santa Catarina, embandeiradas e que, repletas de fiéis, percorrem festivamente tôda a baía ao som das sirenes e ao espoucar de foguetes e rojões.

\section{* * \\ CAPITULO XLVII. \\ VOCÁBULOS DE ORIGEM TUPI NA HISTÓRIA DE CANANEIA.}

Sendo Cananéia a mais antiga das cidades paulistás e o local em que se assenta conhecido primitivamente como o "antigo porto dos tupis", é compreensível a existência de numerosas denominações de origem tupi-guarani em sua História, sôbre rios, mares, serras, montes, etc. como se pode apreciar da relação abaixo, e cuja significação, de acôrdo com o que dizem os autores nem sempre paracerá justificável. Por outro lado, é natural a corruptela que existe em muitas delas, dada a aproximação ou semelhança com outros vo- 
cábulos, como é fácil observar-se nas palavras Condapui, Caudapui ou ainda Conapui: tapinhoá-pinda que aparece em vários documentos como tapanhapina e tapanhapima; boguassú, que alguns interpretam como boy-guassú ou biguassú, dúvidas essas que devem ser resolvidas pelos nossos tupinólogos.

São êles:

Acaraí; nome de um pequeno rio de água salgada, existente na parte ocidental da ilha de Cananéia, cuja significação nenhuma dúvida oferece, uma vez que as letras $u$ ou $i$ no fim dos vocabulos, servem para designar água.

Temos assim que acaraú, será a água, ou melhor, o rio dos acarás, da mesma forma que Ananaú, serve para deneminar o rio dos ananás.

Em documentos oficiais aparece também a palavra Nanaú cujo significação é a mesma. Temos ainda aratuú, ou rio dos aratús.

Araçaúba. Com esta denominação existem um rio e serra, no extremo sul do município. Aracaúba, deve ser corruptela de Arą̧atubo, sítio, lugar onde existe abundância - tubo, de araçás, como diz Teodoro Sampaio.

Ararapira, nome da antiga povoação, ora pertencente ao Paraná. Segundo alguns autores, Ararapira quer dizer pele (com penas) das araras. Para outros, porém significa - sítio abundante de peixes (pira) e araras. Teodoro Sampaio interpretou como - a cabaceira das araras.

Aratáca, como que para significar "pontas desatadas", armadilha para caça miúda, segundo o mesmo autor. Deve ser palavra onomatopáica, como diz J. David Jorge.

Aratuú, rio dos aratús, pequenos crustáceos que sobem nas arvores do mangue, o mesmo que aratá.

Arirí, sede do Distrito de Paz criado em 1920, em substituição ao de Ararapira. Para alguns autores, Arirí significa a palma mansa ou mais macia. Ao ser apresentado o Projeto de lei criando novo distrito e dando-lhe essa denominação, não se lhe deu a necessária significação.

Ariviaia, ou Iririaia. Dizem alguns proceder de Airí, acre, azêda, de mau sabor, o sumo do arirí. Entretanto, para Frei Francisco dos Prazeres em seu Glossário de palavras indígenas, significa - palmeira saudável, saborosa.

Assungui. Existem no município um rio e uma serra com êsse nome, de acôrdo com a interpretação dos autores, assungui deve ser traduzido como o rio das areias de ouro, ou então, o rio de água azulada, segundo Frei Francisco dos Prazeres.

Para Teodoro Sampaio, é corruptela de açunguí, o sangue da gente, o rio do sangue.

Assungui-Assú, rio grande das arreias de ouro. Esta interpretação deve ser a mais aceitável, uma vez.que, em suas imediaçōes existiam outrora diversas catas de ouro. 
Boacica, a que outros escrevem Boacéca. E' um dos afluentes do rio Aririaia.

Segundo alguns autores, vem de Boi-cia, a cobra pegajosa, gosmenta. Para outros, porém é corruptela de - mboacica, - o atalho, o corte, como diz Teodoro Sampaio, interpretação esta que nos parece mais aceitável.

Boguassú. Essa é a maneira usualmente pronunciado em Cananéia, entretanto alguns entendem que possa ser uma corruptela de biguassí, que seria biguá grande, ou baguassú, ou boy-guassu, - a cobra grande.

Boprica. De acôrdo com os tupinólogos, êste vocábulo significará vento que arrebenta, que estrondeia. E' o nome de um pequeno sítio da ilha do Cardoso.

Brocutanho, nome de um sítio e córrego ao norte da cidade. Teodoro Sampaio, Frei Francisco dos Prazeres, João Mendes e outros nada dizem quanto à sua significação, que nos foi fornecida por um amigo J. David Jorge, como sendo roça das almas.

Bupéva, como é conhecido o sítio onde teve início o Convento dos Jesuítas.

Há uma Sesmaria em cuja carta se lê Ubupeba. Ao que se presume deve ser corruptela de $Y b i$-pebo, a terra baixa a planície mais aceitável, ou boi-peba, a cobra ordinária, que não nos parece procedente,

Camboriú. Esta a maneira pelo qual se conhece e é pronunciado o vocábulo, em Cananéia.

Entretanto, pode ser interpretado das seguintes formas:

Camborupú, para significar a fonte. De Cambú-apú.

Camboriú, de cambi-ri-ú, rio onde corre o leite.

Camuriú, de Camuri - robalo, e $u$, rio isto é, o rio do robalo, fórmul a que nos parece mais aceitável.

Caudairó. Nome primitivo do Morro de São João, ao lado da cidade. Não encontramos nenhuma referência sôbre o vocábulo, a não ser uma simples citação feita por João Mendes de Almeida.

Existe um peixe de rio chamado - canderú, - cujo nome, ao que nos parece, nenhuma relação deve ter com o vocábulo em apreço. Caguassú, corruptela de caa-guassú, - o mato grosso.

Caiguéra, costeira situada no Baixio. Ao que dizem os entendidos - vocábulo significa queimada extinta, antiga.

Cangioca, corruptela, talvez, de cang-I-oca, casa do rio do côco, isto é, onde existiam muitas palmeiras. Poderia ser, também, cai-gi-óca, a casa do rio da queimada ou ainda, cangi-óca, a cobertura frágil. Preferimos a primeira, isto é casa do rio do côco.

Canguri, para denominar um pequeno rio que desagua no mar do Cubatão.

Canha, rio e morro. Rio das cavernas, segundo alguns autores o sumido, por se meter entre pedras. 
Capivaru, rio das Capivaras, o mesmo que capivari.

Cóti-caen ou Coticae, sítio e canal na ilha de Cananéia.

Camborússú, quer dizer o pote grande.

Cananéia, nome bíblico. Vide capítulo especial sôbre o vocábulo.

Condapui, Candapui, o enroscado ou retorcido, fino; rio bastante sinuoso, que percorre quase tôda a ilha Comprida, na direção do sul para norte. Desagua no Mar Pequeno.

Alguns documentos trazem a grafia - Canapiu, - como que a significar o rio das cauas, como se vê em, antigas Sesmarias.

Seria uma palavra híbrida, formada de cana (portuguêsa) e puy, de origem tupí.

Outros escreveram - Conapui, isto é, o rio dos meros, o rio dos conapús.

Para João Mendes seria Cóndapui, - corruptela de Cundaá, torto sinuoso e puy, profundo, $y$, rio.

Carapára, - o acará torto. Rio que desagua no mar do Trepandé. Cubatão, têrmo africano, de cubata, casa de negro.

Guaraú, rio dos guarás, das garç̧̧as.

Guaruvi, rio. Segundo alguns autores o referido vocábulo serve para significar pequeninos peixes esverdeados, guarú verde.

Guaxixi ou guacia, nome de um pequeno rio de ilha de Cananéia, que desagua no Mar Pequeno e que, para alguns, significa - mâi dos viventes.

Guarapariçu, para designar o cercado grande das garças ou dos guarás.

Outros vocábulos semelhantes, para designar lugares, da ilha de Cananéia, são:

Guaraparim, que quer dizer a garça mansa ou de pernas quebradas, como nô-lo revela Teodoro Sampaio. E' nome de uma ilha na baía de Trapandí.

Guarapari, que se confunde com o precedente e tem o mesmo significação.

Guaratuba, costeira, cuscada. Abundância de guarás.

Guarú, nome dado a um pequenino peixe também conhecido como barrigudinho. $O$ vocábulo quer dizer, - comedor.

Iconha, nome de um rio do Município .

Iguatemi, rio sinuoso, com muitas voltas.

Indaiatuba, sítio onde ha abundância de indáias.

Ipanema, água ruim ou como significativo de mau para a pesca. Iririu, rio da ostra.

Itaquatidra, nome primitivo da ilha do Cardoso, com relação talvez com marco colocado na ponta de Itacurusá.

Itacurussá, pedra desenhada, escrita, como significação do marco ou padrão ai deixado pelos portuguêses, onde está desenhada a cruz de Cristo.

Itapitangui, pedras vermelhas ou avermelhadas.

Itinga, ou Utinga, água branca.

Jacareui, rio dos jacarés. 
Jaguaquara, esconderijo das onças. João Mendes diz ser môrro ponteagudo. Para Teodoro Sampaio é a cova da onça.

Japaguareú, rio dos tigres.

$J a p a j a ́$, sítio; é possível que seja uma corruptela de $j a b a-j a$, isto é foge-foge, esconde-esconde ou esconderijo.

Juirí, diz João Mendes ser afluente do Itapitanguí, rio baixo, alusivo a ficar totalmente sêco.

Juriu segundo o mesmo autor é corruptela do Iririú, rio da água escura. As águas tem sabor da pedra-hume.

Jurúba, pescoço amarelo.

Jurukessaba, deve ser corruptela de ajurú (papagaio), mais quersabo $($ ninho $)=$ ninho dos papagaios.

Juruvaúva ou Juruvaúba, deve ser corruptela de jerivá-úba, fruto do jarivá. Magé, diz Teodoro Sampaio; o feiticeiro ou pagé, com referência à residência dêste, o mesmo que bagé, pagé, etc..

Mandira, rio (peixe fluvial-mandí).

Nanaú, rio dos ananazes, onde há ananáz.

Nhundiaquára, a toca dos peixes nhundiás. A morada dos jundiás, o berço do peixe dêste nome, segundo Teodoro Sampaio.

Nhupaum, ilha do campo, isto é, capoeira.

Paratiu, rio dos piratís, das tainhas.

Perequê, ou melhor, pirá, peixe, iquê entrada, rio onde os cardumes de peixe costumam entrar.

Pindaguá, vale ou baixa dos gauchos ou anzóis.

Pindauva, (rio, morro) anzol de metal amarelo.

Pirotinga, talvez pira-tinga môrro no destrito de Arirí, peixe branco, tainha.

Sabiacó, roça dos sabiás.

Saguassú, olho grande.

Sambaqui, ou tambaqui, depósito de cascas de ostra, mexilhão, mariscos em geral, depósito de moluscos.

Taboãa, diz João Mendes "alusivo a ter leito empinado" (palavra portuguêsa).

Tajuva, pau, tronco amarelo.

Tapitangará, rio das pedras vermelhas.

Tabatinguára, sítio; segundo João Mendes o corredor da tabatinga.

Taperocu, tapera grande.

Tapinhod, pinda ou tapanhapima. Serra e pedra escabrada no alto da serra.

Taquarí, rio das taquaras, cana brava.

Timbopeba, rio, cipó chato, timbó.

Trapandé, bahia; diz João Mendes, ser vocábulo alusivo ao arquipélago dêsse nome.

Ubatuba, muitas ubás, canoas.

Vamiranga, corrupção de ubá-piranga, fruta vermelha, ibá-piranga. 


\section{CAPITULO XLVIII.}

\section{PROVIMENTOS DOS OUVIDORES.}

Capitulos antigos dos ouvidores gerais q' vieram de corriçam desta $\mathrm{V}^{\mathrm{a}}$ cujo theor e forma é o seguinte/

Aos vinte e sinco dias do mes de Setembro de mil e seis sentos e setenta e sinco annos nesta vila de Sam Joam Bautista de Cananea na Caza da Camara dela estando ahi prezente Ouvidor geral desta Repartisam do Sul o doutor Pedro de Onhate Castelo Branco e os officiais da Camara deste prezente anno ao diante asignados pelo dito ouvidor geral foi feita em a Correiçam e os Capitulos dela sam os seguintes de que fis este termo eu Luis Fernam Casthelo Branco escrivão da Camera o escrevy.

Primeiramente por ser esta a $\mathrm{pr}^{\mathrm{a}}$ Correiçam que nesta Vila cocomeça fazer o ouvidor geral e ser nescessaria ao serviço de Sua Alteza, da Camera e os da justiça e as mais digo de S. A. e bem deste Povo haver forma e modo com que os officiais da Camera e os da Justiça e as mais sem este segurar nem se atalharem tantos encovinientes e os beis dos que nesta villa se praticam asi contra a jurdisam Real e boa administrasam da justissa como na destruibuisam das Rendas de seu elehito Ouvidor geral os provimentos seguintes.

Em $\mathrm{pr}^{\circ}$ lugar por quanto na Camera desta Villa se não olha pelas ordenaçam proveo ele Ouvidor geral que logo se cumpraçe pellos officiais da Camera que actualmente estam servindo se the dará em culpa e a coais quer outros que a não comprarem o que cumpriram dentro em outo mezes da data destes e guardaram o $\mathrm{L}^{\circ}$ 66 / e o L.o 67 / e o L.o 68 / e o L.o 69 / e o L.o 70 / e o L.o 71 / e o L.o 72 / da dita ordenaçam em que se constam o L.o dos Vreadores e da forma das eleiçóens e Regimento do Procurador do Concelho e dos almotaceis e delhe $2 \ldots$ do Concelho e do escrivão da Camra //

Proveo mais que avendo pesoa abonada nesta $\mathrm{V}^{\mathrm{a}}$ a obrigacem thizoureiro e qual quer que servir guardara o $\mathrm{L}^{9}$. / do Livro primeiro da ordenasam //

Proveo mais que logo se fizese hua Arca com duas chaves em que se meteram todos os forais, tombos privilegios e quaisquer outras escrituras que pertenseram ao Concelho e hu Inventario dos ditos papeis e hua chave huma ao escrivão da Camera e outra hu Vereador //

Cap $^{9}$ - 5- Proveo mais que a custa do dinheiro dos orfãos se fizesem logo hua arca com tres chaves em a qual se metese o dinheiro dos orfãos e quais quer pesas que tiverem de prata o ouro ou as escrituras do dinheiro que se der a ganhos e que sejam de pesoas abonadas e fiadores e abonadas aliás a pagarem eles e seus SoçeSores de sua Caza e não avendo pesoa abonada, sirva de Thizoureiro o procurador do Concelho e hua chave terá o Juis de orfáos e a outra o depuzitario e outra o escrivão dos orfãos // 
$\mathrm{Cap}^{\circ}$ - 6- Proveo mais que se fizese outra arca a custa dos bens do Concelho com tres chaves na qual se despozitará todo o dinheiro pertencentes ao Cenado digo do Concelho he hua Chave terá o vereador mais velho e outra o escrivão e outra o Tizoureiro //

Cap ${ }^{9}$ - 7- Proveo mais que no Receber e despender deste dinheiro guardasem a forma da Ordenaçam do L.o $\mathrm{pr}^{9} \mathrm{tt}^{\circ} 66 \mathrm{f} .35$ e o mais titulos atras referidos $/ /$

Cap $^{\circ}-8-$ Proveo mais que os Juizes dos orfãos digo os Juizes ordinarios guardasem a ordenansçam do $\mathrm{L}^{\circ}$ primeiro $\mathrm{tt}^{\circ} 7 \mathrm{~V}$.

$\mathrm{Cap}^{9}$ - 9-Proveo mais que 0 Juiz dos orfãos guardase a ordenaçam do $L^{9}$ $\mathrm{pr}^{\circ} \mathrm{tt}^{\circ} 8 \mathrm{~V}$.

Cap $^{9}-10-$ Proveo que o escrivão da Camera guardaçe a ordenaçam do $L^{\circ}$ $\mathrm{pr}^{\circ} \mathrm{tt}^{\circ} 71 / /$

Cap $^{9}$ - 11 - Proveo mais que os Juizes ordinarios obrigasem ao escrivão e tabaliam e dos orfãos não sirvam sem Regimento os coais mandaram buscar ao Rio de Janeiro alias se lhe daram em culpas a huns e aos outros //

Cap $^{0}-12$ - Proveo mais que os officiaes da Camera não ponhão tributo algum ao povo em fazendas sequas ou Comer ou de beber nem lhe lancem fintas ou pidido sem expreça ordem de Sua A ouvidor Geral por ser culpa grave o fazerse ao contr $\% / /$

$\mathrm{Cap}^{9}-13$ - Proveo mais que por quanto para se pagar o donatario da Sua A. se leva de cada pipa de aguardente tres mil reis de tributo aos frasteiros, e tres mil reis aos moradores da terra todos de cada pipa de molhado e de cada peça de pano de algodam hua pataca ouve o dito Ouvidor geral por bem que os ditos tributos se continuasem até nova ordem de A. A. aq.m ele ouvidor geral o fará prezente pagaram os porteiros tres mil reis e os moradores outros tres de toda co hua pataca de cada Rolo//

$\mathrm{Cap}^{\circ}$ - 14- Proveo mais que se fizeçe hu livro e que serviçe de nele se escrever as entradas de todas as ditas fazendas de que se pagaram os ditos tributos os coais deram os mestres das embarcações sem ma digo dezembarcarem couza alguma delas aliás sejam prezos a cadea $\mathbf{e}$ paguem em dobro o que dezembarcarem só por não virem dar ao dito avizo despois de ancorarem doze horas estavam prezos na $\mathrm{Ca}$ dea hu mes e coando mereçam digo quando vierem manifestar a tais fazendas declararam a cantidade e a cantidade e a calidade dels pelos seus livros e asim mais todos o mais que troxerem fora delas alias pagaram em dobro na Cadea o que se provar ocultarem e em todas e em todas estas materias escreverão digo o escrivão da Camera e de tudo fará asentos no dito Livro reportando-se aos papeis que se prosesar que ficarem em sua mão //

Cap ${ }^{\circ}$ - 15 - Proveo mais que os abatimenttos que se fizerem dos que tras das ditas fazendas não façam os Juizes sem sumaria de duas testemunhas do que tudo fará o escrivão asento no Livro Reportando-se ao ditto Sumario sendo comvenientes aliás o pagaram os que fizerem os que tras // 
Cap ${ }^{0}$ - 16- Proveo mais que se faça carga cada anno no dito Livro de que tudo o que entrar e se cobrar em titulo de per Sy e logo em outro Livro as despezas em titulo de per Sy em cada anno //

Cap 917 - Proveo amis que todas as despezas se faram por m.tos paçados por acordão asignado por todos os Vereadores que se acharem prezentes e feitos pelo escrivão da Camera declarando pera que cauzas sam e com quitaçoins de que recebeu digo nas costas do dito mandado, sendo a despeza na forma da ordenaçam; e da outra sorte os pagaram os que amndaram pagar //

$\mathrm{Cap}^{0}-18$ - Proveo mais que as despezas se fizesem na forma da ordenaçam do L.o e $\mathrm{tt}^{\circ} 66 \mathrm{f} .35$ athe a f. $48^{\circ}$ e do $\mathrm{tt}^{\circ} 62967$ athe o $877 \mathrm{sem}$ gastarem mais em Igreja nem emprosiçons se não na forma que a dita ordenaçam..despoem e faram somente tres prociSoins hua de Corpo de Deos outra a dois de Julho a outra da Vizitasam de Nosa Senhora outra no trecero domingo do mes de Julho por Comorasam do anjo da guarda na forma dos ditos para grafos da dita ordenasam //

$\mathrm{Cap}^{\circ}$ - 19 - Proveo mais que as Condisoins que fizerem os almotaceis na forma de seu Regimento se asentem pelo escrivão da Camera no $L^{\circ}$ da Receita daquelle anno //

Cap ${ }^{\circ}-20$ - Proveo mais que não consintão na Camera asistir Capitam mór algum nem Ouvidor nem prelado nem Vizitador, nem Vigr ${ }^{\circ}$ nem outra algua peSoa mais que os officiais da dita Camera e Ouvidores gerais postos por S. A. por ser o contrario contra a Jurisdisão Real //

$\mathrm{Cap}^{0}-21$ - Proveo mais que não deixasem exersitar Jurisdisão algum nesta Vila ou em seu termo nem examinar as barras asim governadores Capitans mores, provedores Thizoureros, almoxarifes tabalioins, escrivains proteiros, meirinhos, alcaides, dizimeiros como quais quer outros cargos ou officios sem Registarem nas Cameras os poderes provimentos que pera isto tem, e se sam pasados por quem poder tenha para iSo e não obedesendo ou excedendo os poderes the $\mathrm{m}$ pidam e mão obedesendo os prendam e remetam ao ouvidor geral //

$\mathrm{Cap}^{0}-22$ - Proveo mais que os officios deescrivão e tabalions, alcaides, meirinhos e quais quer outros oficios da fazenda ou da justiça não consintam que os Capitains mores os provejam e provendo os notifiquem os providos que não uzem deles e não obedesendo os prendam não mostrando ordem de S. A. expreça os ditos Capitains mores pera fazerem os tais provimentos por quanto toca somente dos Ouvidor geral os tais provimentos de servintias e suSedendo ser neçesario prover alguns dos ditos officios a Camera os provera dará logo conta ao Ouvidor geral pera os prover apontando the os sogeitos melhores que foram dentro em dous mezes alias se the daram em culpa o que só lhe premita por ser distante' o Rio de Janeiro donde asiste o ouvidor geral //

$\mathrm{Cap}^{0}-23$ - Proveo mais que não deixem ao Vigr.os ou prelados eclesiasticos tomar a jurisdisam Real obrigando os lugares / digo os leigos nas cauzas em que lhe não pertence o que Responhão perante eles sendo nos cazos conteudos na ordenasam L.o $2^{\circ}$ tt 9 nem os seculares sejam sitados perante Ley por dividas Sives ou Crimes em que os 
Seculares seijam Reos e que os Vigarios nem Curas mandem pagar dividas ou as obriguem a pagar e procedendo lho empidam e sesurando as agravarem pera ouvidor geral como Juis dos efeitos da Coroa de que S. A. aprovem por bem dos povos aliás se lhe dará Culpa por ser contra a jurisdiçam Real p.r outro sim lhe não consentirem que tomem conhecimento dos bens ou Rendas da Camera ou de quais quer outros do povo ou sentensas por comsintirem em seu juizo //

$\mathrm{Cap}^{\circ}$ - 24- Proveo mais que todos aqueles os quize dias se ajuntem em Camera todos os Vereadcres mais que todos aqueles os quize dias se ajuntem em Camera todos os Vereadores Juizes e Procuradores escrivam e o que faltar pagaram hua pataca que o escrivão será obrigado a carregar em o Livro e o procurador o Requerelo e a cobrala aliás se lhe dará em culpa e todos os bens do Concelho que por sua negligencia se puderem os pagaram //

Cap $^{9}-25$ - Proveo mais que os Mercadores e vendilhoins dem fiança comforme as fazendas que venderem e os mais officiais a quem se dam outros a fazer e a filem as medidas pera que eles alegaram digo algaram hu afiridor e Registaram as escritas pero escrivão da Camera que levara de cada hu coarenta reis e pela fiança que tomar em o Livro coatro vinte reis e declaram as ditas licenças as fazendas que querem vender para comforme isso ser a fiança //

Cap $^{9}-26$ - Proveo mais que os officiais mecanicos lhe dem Regimentos de todas porque ande fazer as obras //

$\mathrm{Cap}^{\circ}-27$ - Proveo mais que sirva o Vereador mais velho no anno seguinte procurador por ser asim cõveniente para darnoticia das Rendas que entram de novo e das mais cauzas pretencentes a Camera //

$\mathrm{Cap}^{\mathrm{0}}$ - 28 - Proveo mais que os Juizes ordinarios Camera e ouvidores não soltem os prezos nem lhe dem a Villa por prizam, tendo prezos por cauzas crimes ou sives que não cabem em sua alçada nem lhe conceda fiança alias se the dara em culpas //

Cap $^{9}-29$ - Proveo mais que os Juizes Ordinarios obriguem aos escrivaens a que tenham dous livros emcadernados e Rubricados por hum dos Juizes he que se escreva as ditas as tesmunhas perguntadas sobre os ditos autos e não tomaram mais que coatro testemunhas em cada crela ou queixa devasas as faram e tiraram em feito a parte como fazem tirando trinta testemunhas fora Referidas se preguntaram, no Cabo escreveram os escrivains aos feitos e autos e outrosim obrigaram os tabaliains que tenham hum livro de notas Rubricado por hu dos Juizes, emcadernado no qual escreveram as escrituras de Contratos ou distratos que fizerem de procuraçoins ou papeis que mandarem lançar na dita nota e quanto alguma escritura se não aSignar pelas partes se partes não averem o dito tabaliam declarará e por não terem efeito //

$\mathrm{Cap}^{9}-30$ - Proveo mais que nesta villa se não consintise jogos de parar algum e que a Camera fizesse sobre isso particular cuidado recomendando aos Juizes tirem devasa e prendam aos culpados e lhes tomem os dados ou cartas com q' jogarem e o dinheiro que lhe acharem jo- 
gando pera as obras do Concelho e não fasam pagar dividas alguma de jogo de parar //

$\mathrm{Cap}^{0}$ - 31 - Proveo mais que não consintam que dos Juizes se agrave pera os ovidores por quanto não podem tomar conhesimento de tais agravos e que outro sim os ovidores desta Capitania e dos mais não uzem de mais jurisdisam que $o$ que lhe he comsedida pela ordenasão o Livro segundo o $\mathrm{tt}^{\circ} 45$ e 61 debaixo das penas nellas declaradas //

$\mathrm{Cap}^{\circ}-32$ - Proveo mais que todas as terras e Cazas do Concelho se aforem com pençam ou foro convenientes e nos que se derem se faça o mesmo a todas as mais fazendas digo fasam muito por trazerem arendadas asim por ser ou concesão por senhorio o Concelho como pera se aumentarem as Rendas deles visto não ter nenhuma.

Cap ${ }^{\circ}-33$ - Proveo mais que o ovidor desta Capitania não tenha meirinho por quanto os ovidores do donatario não poderam digo não podem ter na forma das devasas se Iho dará em culpa por ser contra a jurisdisam Real //

Cap $^{9}$ - 34- Proveo mais que os officiais da Camera com pena de sincoenta cruzados pera as despezas façam os padroens necessarios na forma da ordenação Livro $\mathrm{pr}^{\circ}$ a $\mathrm{tt}^{\circ} 18$ paragrafo 36 e feitas os padroeins mandem a faze: a Villa da Conçeisam por ser cabesa desta $\mathrm{Ca}$ pitania //

Cap $^{\circ}-35$ - Proveo mais que nam case o demita por Juis pesoa inda que seja de colidade que não são todos nem escrever por do contrario seguir por aver segredo na justiça //

$\mathrm{Cap}^{9}-36$ - Proveo que a pesoa que não manifestar coais quer pesoa fugidas que tiver dentro em outo dias os juizes diguão dentro em oito dias as manifestar aos Juizes ordinarios pera se avizar os seus donos e as retiverem geram de mandados defunto e pagaram oito vintens por dia //

Cap -37 - Proveo mais que os Juizes e os mais officiais da Camera dem cumprimento aos mandados dos ouvidores e ordens suas por que não convem os seus oficiais digo officios Reprovarem por terem Supriores dar conta sob pena de duzentos cruzados pera as despezas da justiça //

$\mathrm{Cap}^{0}$ - 38 - Proveo mais que os almotaceis sirvam os que acabam de officiais da Camera de dous em dous mezes cada hum e se não escuzem para com isso não andar a vara em pesoas que não meresem de que vem a serem desprezadas avendo de fora algua pesoa que meresa querendo se lhe dará o cargo querendo o propitario e por ser da Camera //

Cap $^{\circ}-39-$ Proveo que acudindo os Juizes ordinarios as brigas e a sua vista cada hu se não aquictar pelo respeito da Vara dos Reos os prenda em ferros e prosedam contra eles com autos de dezobedientes e por.. .... espendas pera o meirinho a metade e outra pera o Concelho //

$\mathrm{Cap}^{\circ}-40$ - Proveo que avendo nos tais fugas armas de fogo digo de espingardas de qualquer comprimento que seja ou acudindo algum com ellas lhas tomem e loguo os mandem desfazer pera preguos e obras da Cadea e fechaduras dos alvearos e portas do Concelho e alem disso 
serem prezos e os condenaram em pena do arbitrio do julgador pera a aRecadasam o que faram os ditos Juizes sob penna de emcorrerem nas pennas dos malfeitores //

$\mathrm{Cap}^{0}$ - 41 - Proveo que os Juizes ordinarios e mais justiças não comsintam fazerem se motins nem dizerem o que do povo nem outras cauzas que pareça alteraçam por que isto tem o pareser e especial de traydor estes tais os prendam por traydores e se lhes daram o castiguo que no capitulo a faço se Refere.

Cap ${ }^{\circ}-42$ - Proveo que nos Cazos de morte fugidos da Cadea e outros digo proveo que suseciendo al Cazo de morte ou outra semelhante os Juizes com penna de mil cruzados pera a Relaçam a peti dem toda aRmas e vam sobre elles ditos deliquentes e os prendam e com correntes e prisoins nesesarios os emviem com guardas da Vila em a mesma forma da Dey pera serem castigados e lhe soscretem seus bns //

Cap ${ }^{\circ}-43$ - Proveo que os Juizes ordinarios que nos cauzos de morte figidas da Cadea e outros atrozes os juizes perguntem as det.ts vistas ouvidas ou se outra qualquer sabedoria e com indicios somente prenunciem apreendam e soscretem beins nas cazas de morte e na mesma devasa digam ao escrivão que perguntado e testemunha de ouvila de vista ou otra qualquer sabedoria sob pena de se lhe dar em culpa//

$\mathrm{Cap}^{0}-44$ - Proveo mais que haija outra Caixa de tres chaves em qual se metera a terça parte do concelho na forma da ordenasam $\mathrm{tt}^{\circ} 6256 \mathrm{e}$ se não guastaram as ditas Rendas se não na forma da ordenasam e hua chave terá o vereador mais velho e a outra o tizoureiro e outra o escrivão da Camera //

Cap ${ }^{\circ}-45$ - Proveo mais ela minha do vereador athe donde chega a jurisdisam desta Vila mandem consertar os oficiais da Camera de maneira que a posam servir por elle por ser mais comveniente e bem comim deste povo a preguntar se pera o que nesesitar de ser mais bem limpo do Caminho aberto o que lhe encomendo fasam conta a brevidade e fasam toda a deligencia posivel porque no dito Varadoro esteja hu homem de morada que tendo duas Canoas huma da banda da queoutra da banda de $\mathrm{Ca}$ o qual levara sinco patacas de cada embarcasam o qual mandara o menos com dois negros sempre asy pera esta Vila como pera Pernagua os quais sinco patacas lhe faram pagar os Juizes desta Vila e ultimamente prendendo e executando os passageiros no que trocher em todas as partes que o dono avia negros se qui .......//

Cap ${ }^{\circ}-46$ - Proveo mais que todo o guado andase com pastar e o que emtrase nas fazendas alheyas se acomodasse na forma da ordenasam //

Cap ${ }^{\circ}-47$ - Proveo mais que os Juizes asim como sahiram façam avizo pela primeira embarcaçam ao Rio de Janeiro pedindo as Cartas de Confirmasam ehuzança porem asim como sahirem logo hiram servindo e o faram em coanto as ditas Cartas não chegarem as ditas Cartas não chegarem huzando de sua juridisam e será valido o que fizerem emquanto não tiverem as ditas Cartas.

$\mathrm{Cap}^{\circ}-48$ - Proveo mais que a Camara e Juizes não consintam que os Ouvidores das Capitanias façam Correição por eles ou auto de Correição // 
Capo - 49- Proveo mais que hu Caminho que vay desta Villa pera o Rio da Aldea se conSerte logo por ser frequente serventia dos moradores //

Cap ${ }^{\circ}$ - 50 - Proveo mais que a Camara não gaste dinheiro algum em das embarcaçoens e negros para os pasageros pasarem pera Parnaguá o ..go a pe posto que digam que vam a ordem de sua $A$. por lhes não mandar dar o dito Senhor e se aproveitarem todos com este $7^{\circ}$ para fazerem as ditas pasagens porem mostrando ordem do dito Senhor sem que seja visto mais que sobre escrito lhe daram logo negros e Canoa e pagaram os pasageros que troxerem a dita ordem e só na remeçam dos prezos e ordem de quem poder tenha $\mathrm{p}^{\mathrm{a}}$ mandar a Camara faram despezas da dita Canoa e negros das Rendas do Concelho quando pella dita ordem espreçamente asim se lhos ordene e isto com a mayor moderaçam que posa ser alias de pagarem de sua Caza e se lhe ter em culpa de que se felicitará a ordem do ouvidor geral.

Cap $^{9}-51$ - Proveo mais que por quanto algus moradores se vam desta Vila e desfazem as Cazas que já nella tem feitos e depois em diante não comsintam os officiais da Camara que ceja algua se desmanche nem se lhe desse lhe por ser asim conveniente por ser asim conveniente ao bem publico e os donos somente os podram vencer ou os Renovar //

Cap? - 52 - Proveo mais que o escrivão da Camera se dese mil reis e ao Alcaide tres mil reis e isto cada anno tirando se primeiro o donativo de Sua A. e ao Alcaide coal servira de Carcereiro e pagaram suas carseragem e mais deligencias //

$\mathrm{Cap}^{9}$ - 53 - Proveo mais que visto a Cadea ser fraca que bastam a Rombando os prezos e fugindo dela os oficiais do anno que vem a furtifiquem dorado lhe as paredes e Rodeando a de Vigas fortes humas grades de ferro nem, dortes ou fasam outra Cadea de novo em alta e fortes de paredes com a dita grade de ferro alias se os prezos fugirem emcorreram nas penas que os tais prezos meçam alias os officiais do anno que vem com os que seguirem não acabando a dita Cadea e outro sim tenham dois pares de grilhóes e coatro pares de algemas os coais coando se meterem com os prezos serão obrigados a trazelos que os levar tanto quem os entregar a o otra Camera pera o que se nesesario for deverão o treslado deste Capitulo //

Capo - 54- Proveo otro sim que nenhuma pesoa de qualquer Calidade que seja recolha em sua Caza Indios ou India ser cazado escravo ou escrava sua em sendo será Repreçados a dita Aldea o que se não entendem as queija estam cazados athe não aver ordens dos Ouvidores //

Cap ${ }^{\circ}$ 55 - Proveo mais que por quanto esta therra está muito falto de indios e por esa Rezam está debilitada e falta de moradores em que todos estam pobres por não terem pesas pera tirarem o ouro de lavagem avendo algum nesta therra que he grande prejuizo si bem commum e fazenda Real ordenou ele dito Ouvidor geral que logo os ditos officiais da Camera com homes bons do povo ou por sy fes eleysam em sitio distantes duas leguas desta vila pera Aldea de todos os indios que nesta vila ee seus Reconcovos se acharem serem forros aos quais daram sitio bastante pera fazerem suas Rosas e hu deles elegeram por Capitam $\mathrm{p}^{\mathrm{a}}$ os governar e estarem a sua ordem e a 
dita aldea não estava sobordinada mais que os oficiais da Camera que autualmente servem e quem dela quizer tirar indios pera se servir os não tirará sem ordem dos ditos officiais fazendo pera iso pitiçam e deichando hu termo feito nas costas dela na mão do escrivão da Camera em que se obrigue Repor os indios que se lhe consederem levar na dita Aldea pasados os dias porque se lhe primitiram no mesmo termo a darlhe tres vintens cada dia e de comer o qual obrigaram digo obrigasam faram os officiais da Camera prenderam a todas as pesoas de qualquer calidade que sejam que tiver indio da dita Aldea sem ordem sua e faram pagar dellas des mil reis pera as obras do Concelho e os que levarem com sua ordem e lhe não pagarem nem lhe derem de comer como asima fica dito os prenderam e pagaram em dobro aos ditos indios o Comer e o dinheiro que sam obrigados a dar lhe a os ditos oficiais teram hu livro em q' asentaram os ditos indios e poram dar ua nos que morreram com sertidam do parroco que a aprezentaram nas Correisoins acresentaram os que naSerem e he emcomendo muito esta deligengia da parte de Sua Alteza por ser em aumento deste paroco e os Juizes tenham cuidado de verem os testamentos tanto quie nelles se deixarem algum indio forro ou seus berem que as sam lancm logo ao Rol no dito Livro para ante os mais officiais da Camara e os poram na dita Aldea na forma dos mais aliás do que o contrario fizer do conteudo neste Capitulo ou se provar no tempo em que sirvio se fes o contrario ou se serviram dos ditos indios contra a forma delles e lhe dara em culpa e pagará hu indio ou india cada hu delles pera a dita Aldea ficara nela forra //

Proveo mais que esta Aldea ficava em nome de Sua Alteza e como tal lhe recomendava outra vez a Camera Juizes e mais pesoas //

Cap ${ }^{9}$ - 56 - Proveo mais que esta Aldea ficava em nome de Sua Alteza e como tal recomendava outra ves a Camera Juizes e mais pesoas //

$\mathrm{Cap}^{\circ}$ - 57- Proveo mais que os Suçidios se não rematasem em coanto elle ouvidor geral o que esta façam muito eles oficiais da Camera pera que se aRemdem por sermais comveniente a esta Republica //

$\mathrm{Cap}^{9}$ - 58- Proveo que todas as therras e Cazas do Concelho se aforem com pnsam ou foro Conveniente e nas que se derem se faça o mesmo e todas as mais fazeda digo asim fasam muito por trazerem arendadas asun por ser Reconheser por senhorio o Concelho como pera se aumentar as Rendas delle visto não ter nenhuas //

Cap $^{9}-59-$ Proveo mais que por quanto se lhe tem Reprezentado que esta Vila tem muito limitado descrito e não sam capazes as honrras do Concelho pera livremente se trazer o gado e lavrar que os officiais da Camara fasam medir mea legua de therras pera o Concelho donde steja por dar e que nas therras do Concelho traga cada hu livremente $o$ gado que quiser $e$ lavre as bemfeitorias que lhe pareser $\mathrm{p}^{\mathrm{a}}$ as quais os officiais da Camera lhe aSignaram destritos e lhes faram pagar foro deles cada anno pera a Camera e do gado mesmo modo a tanto por cada cabesa comforme pareser os ditos officiais da $\mathrm{Ca}$ mera e os quais se acharem depois dentro na mea legoa que mando tomar do distrito pera o Concelho do mesmo modo querendo con- 
tinuar com suas lavoras pagaram foro ou despegaram e nunca se poderam a tomar a pose pera o que todos os annos pasara a $\mathrm{Ca}$ mera licença de aRendamentos e quem tiver e quem tiver lavoras pera os defender do gado nas therras do Concelho srá obrigado a taparse e não os criadores a pastar o seu gado //

$\mathrm{Cap}^{\circ}-60$ - Proveo mais que os tres mil reis de Suçidios que os moradores e frausteiros de cada pipa de Aguardente como ele provedor atras ordenou as paguem quando lhe vier as ditas pipas ou dem fiança e sem isto se lhe nam deixe vender a dita Aguardente e se proceda contra lhe oponham //

SeRamento E por esta maneira ove elle dito Ouvidor geral sua Correiçam por acabada estando os officiais da Camera presentes que com eles asignarão de que fis este termo eu Luis Ferram Castello Branco escrivão da Camera o escrevy // Pedro unham Casthelo Branco // Paulo Teixeira // Bernardo de Matos // Ignacio do Canto de Almeida // Agostinho de Farias Correa // João Rodrigues Freitas e Antonio Monteiro //

Capitulo do Doutor e dezembargador

Sindicante Joam da Roxa Pita mandou

fazer cujo theor é o seguinte

Cap ${ }^{\circ}-1$ - Ordenou o dito dezembargador Sindicante que se guardase os $\mathrm{Ca}$ pitulos que aviam feito o Doutor Pedro de Unham Castello Branco sobre as entradas das fazendas qie pagavam Sucidio e que no livro de ..... das fazendas que pagavam suçidio e que no livro se asentasem não só o numero das fazendas mais das pessoas a quem tinham remetidos para que das tais pessoas se cobrase o emposto do donativo sem embargo de que as ditas pesoas trespassasem as fazendas a outras //

$\mathrm{Cap}^{9}$ - 2- Ordenou mais que se os mestres dos dos navios barcos e Canoas que troxerem as ditas fazendas as ocultasem algumas fazendas e desem entrada de menos da que traziam a .... sem toda para a fazenda Real e ficasem obrigados a mais penas que por ste cazo lhe estam detreminado //

$\mathrm{Cap}^{0}$ - 3- Ordenou mais que os officiais da Camera que não desem comprimento nestes Capitulos não pode em nenhum tempo servir nesta Republica porque digo nesta Republica algum oficio della por qur os avia por emcapas dos servisos do principe Nosso Senhor e da Republica e que a coal quer tempo que se alegassem estes empidimentos nas imposiçoins ordirarias se lansasem fora delas ainda da que estiver sem eleitos com todos os botos (votos) e que Relevava aos que athe agora tinham servido destas penas pelas pela noticia que tinham da forma desta cobrança //

Cap $^{\circ}$ - 4- Ordenou mais que se entregasem a Dom Rodrigo Castello Branco o dinheiro do donativo que está depozitado na mão do Thizoureiro Paulo Teixeira e que com sua quitaçam em forma digo nesta comformidade ouve elle dito Sidicante estes Capitulos por acabado que mandou se cumprisem como nele se continha e asignou comigo eu 
Manoel daguiar escrivão da Alsada que o escrevy // Joam da Roxa Pita //

Capitulos que deixou o doutor e ouvidor geral

André da Costa Moreira cujo theor e

forma é o seguinte

Aos seis dias do mes de novembro de mil e seis sentos e oitenta e dous annos nesta Villa de Sam Joam de Cananea Capitania de Nosa Senhora da Conseisam de Itanhaem na Camera dela estando ahi prezente o Doutor André da Costa Moreira ouvidor geral da Repartiçam do Sul e Corregedor da Comarca e bem asim os oficiais da Camara que nella servem este prezente anno a saber Juis ordinarios Manoel da Silva e Paulo Teixeira e Vereadores Francisco Gomes Sobral e o Curador Pedro de Medina Cardozo e procurador do Concelho Manoel Fr.ra Crus logo pero dito Ouvidor geral foi feito hua Correisam e provimentos dela na maneira seguinte de que fis este termo Luis Ferram Castello Branco escrivão da Camera o escrevy //

$\mathrm{Cap}^{9}$ - 1 - Fes pergunta o dito Ouvidor geral e se dera comprimento aos provimentos da Correisam pasada pelos oficiais da Camera foi dito que lhe tinha dado compreimento e pelo dito ouvidor geral foi mandado que se observasem os ditos Capitulos exeto o por que lhe he ordenado que se não de cumprimento aos provimentos que os Capitaens mores fazem pellas procuraçoens que trazem dos donatarios pellos poderes que the dem as suas doasoins //

$\mathrm{Cap}^{9}-2$ - Proveo o dito Doutor Ouvidor geral que por quanto hera emformado que nas Villas sercumvizinhas a esta custumavam os forasteiros pagar de Suçidio tres mil reis como nesta o faziam e que os moradores das pipas que compravam digo pagavam dous mil reis e nesta tres como os ditos frosteiros e avendo respeito o dito ouvidor geral a esta desigualdade e adeministrasam dos Cabedais deste povo mandou que daqui em diante pagasem os moradores dois mil reis do dito Suçidio na Conformidade em que se pagara nas Villas vezinhas a esta //

$\mathrm{Cap}^{9}$ - 3- Proveo mais o dito Ouvidor geral que por coanto hera emformado que alguns dos moradores desta Villa que compravam aguardentes para vender, e vinhos e tudo o mais de que se custuma levar Suçidio ao qual estavam obrigados se custumam queixar de que se lhes não algumas pipas ou barris e pela perda que tiveram dizem que não am de pagar o dito Suçidio e que visto pelo dito Doutor Ouvidor geral mandou que sem embargo das ditas queixas que podem ser fantasticos e inda que sejam verdadeiras pagem o subçidios das pipas ou barris de que derem esntradas e coanto não queirão satisfazer de boa vontade como sam obrigados os Juizes ordinarios os executem pelo que estiverem devendo sob pena de vinte cruzados aplicados para as despezas das justiça e se the daram m culpa //

$\mathrm{Cap}^{\circ}$ - 4- Proveo mais o dito Ouvidor geral o Requerimento do Procurador do Concelho por quanto tinha o dito Comcelho gastos asim pelo que Requereo a ele dito Ouvidor geral que visto em outras partes se 
pagar alguns Suçidios das fazendas secasse puzese ou lançase as que vierem a esta villa alguma quantia honesta e pello dito ouvidor geral foi dito que não comvinha vender a esta villa já tinham paguos dividas na alfandiguas //

Capo - 5- Proveo mais o dito Ouvidor geral que por quanto na ultima correiçam que nesta villa se fes deixou o ouvidor geral provimento que o Vereador mais velho que se prezente serve ficase no anno susequente servindo de procurador do Concelho e porque a este servindo digo a esta espiriencia tinha mostrado o dono que se seguia aos ditos officiais em servirem dos annos continuos e ser esta Rezelva com contia a dispocisam sa ley por que manda que não posam servir dittos officiais de que o ser este paso lemitado e de poca gente as mesmas pesoas com pola entre pelação ordinariamente servem no Concelho pelo que mandou o dito ouvidor geral se não uzase do dito provimento porem que nas eleiçoens se ouvese Respeito a fazerem procuradores pesoas que já aviam servido de Juizes //

Cap ${ }^{\circ}-6-$ E por esta maneira ouve o dito ouvidor geral por feita e acabada.

\section{(Continua).}

